\title{
Thermal resistance of borehole heat exchangers composed of multiple loops and custom shapes
}

\author{
AA Koenig
}

\author{
Correspondence: \\ akoenig@wcupa.edu \\ College of Arts and Sciences, West \\ Chester University, Merion Hall, \\ West Chester, PA 19383, USA
}

\begin{abstract}
Background: The thermal resistance of a borehole can be reduced by employing thermally enhanced grout, increasing the surface area of the loop and locating the legs proximal to the bore wall. Thermal models that are used to predict borehole heat exchange are characterized by either simplified formulations that are restrictive in their application, but utilitarian, or complex multi-dimensional analyses that are cumbersome to implement.

Methods: The borehole resistance methodology presented here offers a straightforward solution that is built on single loop conduction shape factor analysis with thermal shunt accounting and pipe-pipe configuration analysis, to extend to multi-loop borehole configurations and custom kidney extrusions.

Results: The borehole resistance predictions are compared to published data and information listed by manufacturers of multi-loop products in third party thermal tests against standard loops. The results are found to agree within the constraints posed by the model assumptions. The methodology offers a straightforward solution that can be incorporated into popular geothermal loop sizing software such as GLD, GLHEPRO and other system software.

Conclusions: The advantages and challenges of these advanced loop designs are discussed and conclusions drawn. By reducing the bore resistance, one can take advantage of less drilling and proportionally less capital cost for the bore field, while achieving the same loop temperatures.
\end{abstract}

Keywords: Geothermal heating and cooling; Ground source heat pump (GSHP); Vertical loops; Borehole studies; Loop field; Multiple loops in borehole

\section{Background}

One of the challenges to the ground source heat pump market is the cost burden of implementing the ground heat exchange. For the case of closed-loop vertical borehole designs, the thermal barrier presented by a loop can be significant. The high-density polyethylene (HDPE) pipe loop contacts the bore wall via a thermal grout. For example, a $7-8{ }^{\circ} \mathrm{C}$ temperature difference between the water circulating in the loop and the bore wall reduces the heat pump operating performance. In general, the loop legs are not constrained within the bore cross section, and during installation, the legs can twist and contact one another over a substantial portion of the bore length, thereby degrading performance. Typically, the loop is sealed to the bore wall with a bentonite grout mixture, of which the hydraulic and

\section{Springer}

(c) 2015 Koenig. This is an Open Access article distributed under the terms of the Creative Commons Attribution License (http:// creativecommons.org/licenses/by/4.0), which permits unrestricted use, distribution, and reproduction in any medium, provided the original work is properly credited. 
thermal properties are very important to insure optimal performance of the installation. The use of a thermally enhanced grout, while advantageous to heat transfer between the loop and the bore wall, presents its own challenges. For example, the addition of sand to enhance conduction also increases thermal shunting between the legs of the loop and presents challenges in uniform mixing and deployment through a tremie pipe.

Acknowledging these challenges, a study was undertaken to understand the potential benefit of multi-loop and custom extrusion designs which offer greater surface area for heat transfer, while locating the pipe proximal to the bore wall. This borehole design strategy could reduce the capital cost of the ground heat exchanger by reducing the amount of drilling required to serve a load. The contractor or design engineer has the option of either reducing the amount of drilling, while achieving the same end-of-season temperature as a standard loop, or retaining the same well depth and achieving better heat pump seasonal performance. The first approach reduces capital cost of the loop field but retains the same annual savings, while the second does nothing to lower capital cost but rather improves annual utility savings. For example, the building owner might be more interested in lowering the loop field installation cost by $20 \%$ and accepting less annual operating savings. Another strategic advantage might derive from less land utilization and associated mess.

The purpose of this publication is to provide an analytical basis for calculating borehole thermal resistance (BTR) for the case of multiple loops and custom extrusions. The desire is to incorporate the borehole model into existing well field sizing software packages, such as GLD, GLHEPRO, and system modeling software, such as TRNSYS (Klein et al. 1996; Shonder \& Hughes 1997) and HyGCHP, on the market. To accomplish this, the thermal analysis of a single loop (Koenig and Helmke 2014) was chosen as the starting point, acknowledging the contributions of others and developing toward a practical thermal model of a borehole with multiple parallel loops.

Building on the quasi-steady-state modeling (Eskilson 1988) for vertical ground heat exchange, there have been a numerous publications on borehole resistance for a single loop. Previous studies employed finite element numerical techniques (Sharqawy 2009; Sagia 2012; Liao 2012). While these are rigorous, they have also proven to be cumbersome to construct. Others have proposed analytical solutions (Hellström 1991; Gu 1998; Philippe 2010) that are readily applied but are restricted to a limited number of pipe geometries. While these studies support the understanding that increasing the grout thermal conductivity and locating the pipe legs proximal to the bore wall enhances borehole performance, it was left to Redmund (1999) and Beier (2012) to actually demonstrate this fact in field tests. A finite element model for the case of two loops in a borehole was published (Diersch 2010), following the work of Al-Koury et al. (2005). Finally, a recent comparative study of helical pipe and triple U-tube loop designs in foundation pile (Zarrella et al. 2013) is included here, as pertinent to this study.

\section{Borehole thermal resistance for a single loop}

A cross-sectional model of the borehole is shown in Fig. 1. The BTR includes contributions from convection inside the pipe (downcomer and upcomer legs), through the pipe walls and through the media that fills the space between the pipes to the surrounding bore wall. The equivalent resistor network model is given in Fig. 2, where the water temperatures inside the pipe loop legs are designated $T_{1}$ and $T_{2}$, and the surrounding wellbore surface $T_{\mathrm{b}}$. To simplify the analysis, symmetry is assumed in which the pipe spacing is equidistant 


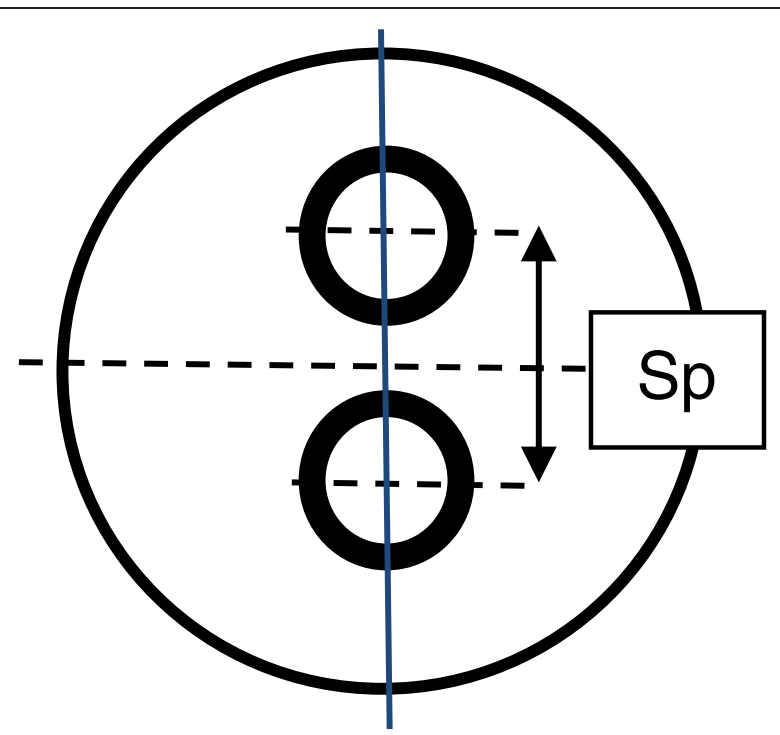

Fig. 1 Conduction heat transfer from a pipe loop to the surrounding bore wall

from the center line of the bore. The resistance for each pipe, $R_{\mathrm{p}}$, is composed of convection at the inside wall and conduction through the pipe wall. The shunt resistance, $R_{\mathrm{S}}$, addresses heat transfer between the pipes through the media, while $R_{\mathrm{f}}$ defines the grout filler resistance between pipe surfaces to the surrounding bore wall.

The temperatures, in general, can all be considered different, such that $T_{1}>T_{2}>T_{\mathrm{b}}$ for the cooling season or $T_{\mathrm{b}}>T_{2}>T_{1}$ for the heating season.

The three equations that describe the resistive network are as follows:

$$
\begin{aligned}
& \left(T_{1}-T_{\mathrm{b}}\right)-\left(q_{1}-q_{3}\right) R_{\mathrm{f}}-q_{1} R_{\mathrm{p}}=0 \\
& \left(T_{2}-T_{\mathrm{b}}\right)-\left(q_{2}+q_{3}\right) R_{\mathrm{f}}-q_{2} R_{\mathrm{p}}=0 \\
& \left(T_{1}-T_{2}\right)-q_{3} R_{\mathrm{s}}-\left(q_{1}-q_{2}\right) R_{\mathrm{p}}=0,
\end{aligned}
$$

where $q$ is the heating rate per unit length. The total heat transfer between the pipe loop and the bore wall is:

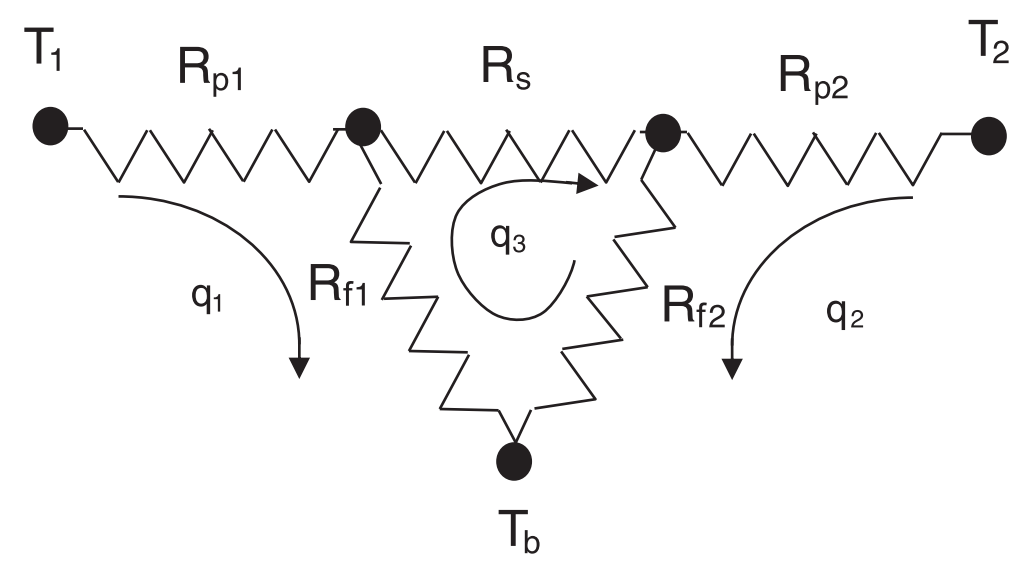

Fig. 2 Resistance network model representing well bore heat transfer 


$$
q_{1}+q_{2}=q_{\mathrm{t}}=\Delta T_{\mathrm{avg}} /\left[\left(R_{\mathrm{p}}+R_{\mathrm{f}}\right) / 2\right] \text {, where } \Delta T_{\mathrm{avg}}^{\circ}\left(T_{\mathrm{avg}}-T_{\mathrm{b}}\right) \text { and } T_{\mathrm{avg}}=\left(T_{1}+T_{2}\right) / 2 \text {. }
$$

The total borehole thermal resistance is defined as $\left(R_{\mathrm{p}}+R_{\mathrm{f}}\right) / 2$.

The three equations can be solved simultaneously for the heating rates using matrix methods:

$\mathbf{q R}=\mathbf{T}$, defined by the vectors $\mathbf{q}=\left\{q_{1}, q_{2}, q_{3}\right\}$ and $\mathbf{T}=\left\{\Delta T_{1 \mathrm{~b}}, \Delta T_{2 \mathrm{~b}}, \Delta T_{12}\right\}$, where $\Delta T$ is the temperature difference designated by the subscripts between the pipes and bore wall. The resistance matrix, $\mathbf{R}$, is:

$$
\mathbf{R}=\left|\begin{array}{ccc}
\left(R_{\mathrm{p}}+R_{\mathrm{f}}\right) & 0 & \left(-R_{\mathrm{f}}\right) \\
0 & \left(R_{\mathrm{p}}+R_{\mathrm{f}}\right) & R_{\mathrm{f}} \\
R_{\mathrm{p}} & \left(-R_{\mathrm{p}}\right) & R_{\mathrm{s}}
\end{array}\right|
$$

developed from Eqs. (1)-(3). The heating rates, $q_{\mathrm{i}}$, are found by taking the product of the inverse matrix, $\mathbf{R}^{\mathbf{- 1}}$, with the temperature column vector. The solution requires an iterative approach, where starting values for the $\Delta T$ s are refined by operating within the simulation of the borehole and surrounding rock thermal storage model in time. The temporal effects of borehole heat capacity are minor (quasi-steady-state), insuring that little time (approximately a day) is required to elapse until the $\Delta T$ s stabilize. Depending on the loop design basis $(\mathrm{m} / \mathrm{W})$, the $\Delta T_{12}$ between the loop legs can be considered to be fixed, e.g., -3.3 or $5.6{ }^{\circ} \mathrm{C}$ for the heating and cooling seasons, respectively. For the parameters listed in Table 1, the matrix solution is found to be $q_{\mathrm{i}}=\{-24.7,-8.03,-4.69\}$ and $\Delta T=\{-7.3,-3.96,-3.3\}$, respectively, for a loop design based on $\left(q_{1}+q_{2}\right)=-32.73 \mathrm{~W} / \mathrm{m}$ for the heating season.

The relative amount of heat shunted between pipe is calculated from the ratio $q_{3} /\left(q_{1}\right.$ $+q_{2}$ ). This turns out to be an important and useful number, because it defines what fraction of the pipe surface area is effective in heat transport to/from the bore wall. This will be apparent shortly in the shape factor analysis of individual pipe heat transfer.

The values for the pipe resistance, $R_{\mathrm{p}}$, the pipe to bore wall resistance, $R_{\mathrm{f}}$, and the shunt resistance, $R_{\mathrm{s}}$, are developed here assuming steady-state conditions. The pipe resistance is composed of series resistances due to convection at the interior wall from water heat transfer and pipe wall contribution. These can be calculated as follows:

$$
R_{\mathrm{p}}=1 /\left(\pi d_{\mathrm{i}} h_{\mathrm{cv}}\right)+\mathrm{LN}\left(d_{\mathrm{o}} / d_{\mathrm{i}}\right) /\left(2 \pi k_{\mathrm{p}}\right),
$$

Table 1 Parameters chosen for this study

\begin{tabular}{lll}
\hline Parameter & Symbol & Size/units \\
\hline Bore diameter & $D$ & $152 \mathrm{~mm}(6 \mathrm{in})$. \\
Pipe size & $d$ & $42 \mathrm{~mm}(11 / 4 \mathrm{in})$. \\
Pipe c-c spacing & $S_{p}$ & $64 \mathrm{~mm}(21 / 2 \mathrm{in})$. \\
Pipe wall (HDPE) & DR & 11 \\
Pipe thermal conductivity & $k_{\mathrm{p}}$ & $0.389 \mathrm{~W} / \mathrm{m}^{\circ} \mathrm{C}\left(0.225 \mathrm{BtuH} / \mathrm{ft}{ }^{\circ} \mathrm{F}\right)$ \\
Pipe thermal resistance & $R_{\mathrm{p}}$ & $0.089 \mathrm{~m}^{\circ} \mathrm{C} / \mathrm{W}\left(0.154 \mathrm{ft}{ }^{\circ} \mathrm{F} / \mathrm{BtuH}\right)$ \\
Grout thermal conductivity & $k_{\mathrm{g}}$ & $0.78 \mathrm{~W} / \mathrm{m}^{\circ} \mathrm{C}\left(0.45 \mathrm{BtuH} / \mathrm{ft}^{\circ} \mathrm{F}\right)$ \\
\hline
\end{tabular}


where the $d$ subscripts (o, i) reflect outside and inside pipe diameters, and $h_{\mathrm{cv}}$ is the convection coefficient for water flowing inside the pipe, and $k_{\mathrm{p}}$, the pipe material thermal conductivity. Note that $d_{\mathrm{o}} / d_{\mathrm{i}}=1 /(1-2 / \mathrm{DR})$, where $\mathrm{DR}$ is the dimension ratio $=d_{\mathrm{o}} /$ $t$, where $t$ is the thickness of the pipe wall.

Similarly, the thermal shunt resistance, $R_{\mathrm{s}}$ can be modeled as pipe to pipe conduction shape factor in an infinite medium (Holman 1981), although the borehole is finite.

$$
R_{\mathrm{s}}=\cosh ^{-1}\left(x_{\mathrm{pp}}\right) /\left(2 \pi k_{\mathrm{g}}\right), \text { where } x_{\mathrm{pp}}=\left[2(S \mathrm{p} / d)^{2}-1\right]
$$

Defining dimensionless quantities: $d_{\mathrm{r}}=d / D$ and $S_{\mathrm{r}}=S_{\mathrm{p}} / d$, the parameter, $x_{\mathrm{pp}}$, can be written as:

$$
x_{\mathrm{pp}}=\left[2 S_{\mathrm{r}}^{2}-1\right] .
$$

For example, Table 1 lists select parametric values in a typical geo-exchange application:

The grout filler resistance between pipe and bore wall is more complicated. Referring to Fig. 2, the shape factor for heat transfer for a single offset pipe to its surrounding cylinder was compiled by Holman (1981):

$$
R_{\mathrm{fs}}=\cosh ^{-1}\left(x_{\mathrm{f}}\right) /\left(2 \pi k_{\mathrm{g}}\right), \text { where } x_{\mathrm{f}}=\left(D^{2}+d^{2}-S \mathrm{p}^{2}\right) /(2 D d) .
$$

where $D$ is the bore diameter, $d$ the pipe exterior diameter, $S_{\mathrm{p}}$ the center to center (c-c) spacing between pipes, and $k_{\mathrm{g}}$ the grout thermal conductivity. Again, this can be defined in dimensionless form as:

$$
x_{\mathrm{f}}=1 / 2\left[d_{\mathrm{r}}\left(1-S_{\mathrm{r}}^{2}\right)+1 / d_{\mathrm{r}}\right] \text {. }
$$

For the selected parameters in Table 1, for example, the pipe to bore resistance is $0.219 \mathrm{~m}^{\circ} \mathrm{C} / \mathrm{W}$. Equation (8), however, is based on a single off-centered pipe conducting to an unobstructed surrounding wall; therefore, one might anticipate that the presence of a second pipe (leg of the loop) would contribute a similar measure, so that the total would simply be half of the single pipe contribution, as suggested by the resistance mesh model given earlier. Unfortunately, this is not quite right in that there is conductive interference due to the presence of the pipe representing the second leg of the loop.

This interference or obstruction is precisely addressed by including the factor, $f$, defined as:

$$
f=1-q_{3} /\left(q_{1}+q_{2}\right)
$$

so that $R_{\mathrm{f}}=R_{\mathrm{fs}} / f$ in the denominator of the pipe to bore resistance, $R_{\mathrm{fs}}$, to correct the thermal influence of each pipe. The total borehole resistance, in this case, is $0.172 \mathrm{~m}^{\circ}$ $\mathrm{C} / \mathrm{W}$. This is composed of parallel contributions of each pipe individually: $0.089+$ $0.219 /(1-0.143)=0.345 \mathrm{~m}^{\circ} \mathrm{C} / \mathrm{W}$, including the pipe and the grout. For the loop, this value is halved to yield the total borehole resistance stated. Note that the pipe legs are at different temperatures, resulting in the thermal shunt of $14.3 \%$.

A closed-form solution for the pipe loop to bore resistance, $R_{\mathrm{pb}}$, develops from solving:

$$
\mathrm{RI}=1 / R_{\mathrm{f}}=2 \pi k_{\mathrm{g}} f / \cosh ^{-1}\left(x_{\mathrm{f}}\right),
$$


where $f=1-\Delta T /\left(q_{\mathrm{t}} R_{3}\right), \Delta T$ is the loop delta- $T, q_{\mathrm{t}}$ the total heating rate, and $R_{3}=\left(2 R_{\mathrm{p}}+\right.$ $\left.R_{\mathrm{s}}\right)+\left(R_{\mathrm{p}} R_{\mathrm{s}}\right) / R_{\mathrm{f}}$

The latter results from solving the matrix equations for $q_{3}$ in terms of the heating rate difference $\left(q_{1}-q_{2}\right)$.

The quadratic solution is:

$$
\mathrm{RI}=-1 / 2\left(a / b-1 / R_{\mathrm{f}}\right)\left\{1-\mathrm{SQRT}\left[1-4\left(c / b-a / b R_{\mathrm{x}}\right) /\left(a / b-1 / R_{\mathrm{fs}}\right)^{2}\right]\right\},
$$

where $a=\left(2 R_{\mathrm{p}}+R_{\mathrm{s}}\right), b=R_{\mathrm{p}} R_{\mathrm{s}}, c=\Delta T /\left(q_{\mathrm{t}} R_{3}\right), R_{\mathrm{fs}}$ and $R_{3}$ as defined in (8) and (10), respectively.

The final borehole resistance (BTR) for a single loop has a closed-form solution that is summarized by:

$$
R_{\mathrm{b}}=\left(R_{\mathrm{p}}+R_{\mathrm{f}}\right) / 2 \text {, where } R_{\mathrm{f}}=1 / \mathrm{RI} \text {. }
$$

The benefit of the closed-form quadratic solution is that it avoids the need for the $\mathbf{T}$ information, which requires the full bore simulation, by providing a steady-state value for $R_{\mathrm{f}}$ straightaway. The two approaches give the same result, with the matrix solution offering additional information on $\mathbf{q}$.

\section{Comparison to others}

In prior work (Koenig and Helmke 2014), which provided a comparison to other reported models, a similar approach was employed to assess single-loop BTR, with the difference being in the use of a geometric obstruction factor, $f(\beta)$. The comparison, while quite good for larger separations, was shy of reported results for cases in which the two pipes were close to one another. As Fig. 3 demonstrates in a comparison of obstruction factors, the discrepancy is confined to the use of a geometric obstruction factor for pipe separations within $35 \%$ of the bore diameter.

A comparison of this improved model to the results of Sharqawy, shown in Fig. 4, clearly shows a very good match over the full extent of the pipe separation study. Note, at $S_{\mathrm{p}} / D \approx 0.28$, the bore resistance experiences a jump as the pipe legs actually contact. This result lends credence to the model proposed here.

Figure 5 demonstrates the benefit of employing higher conductivity grout (reported in $\mathrm{W} / \mathrm{m}^{\circ} \mathrm{C}$ ) as well as increased pipe separation in lowering borehole resistance. Even though thermal shunting increases with higher grout conductivity, the impact of greater

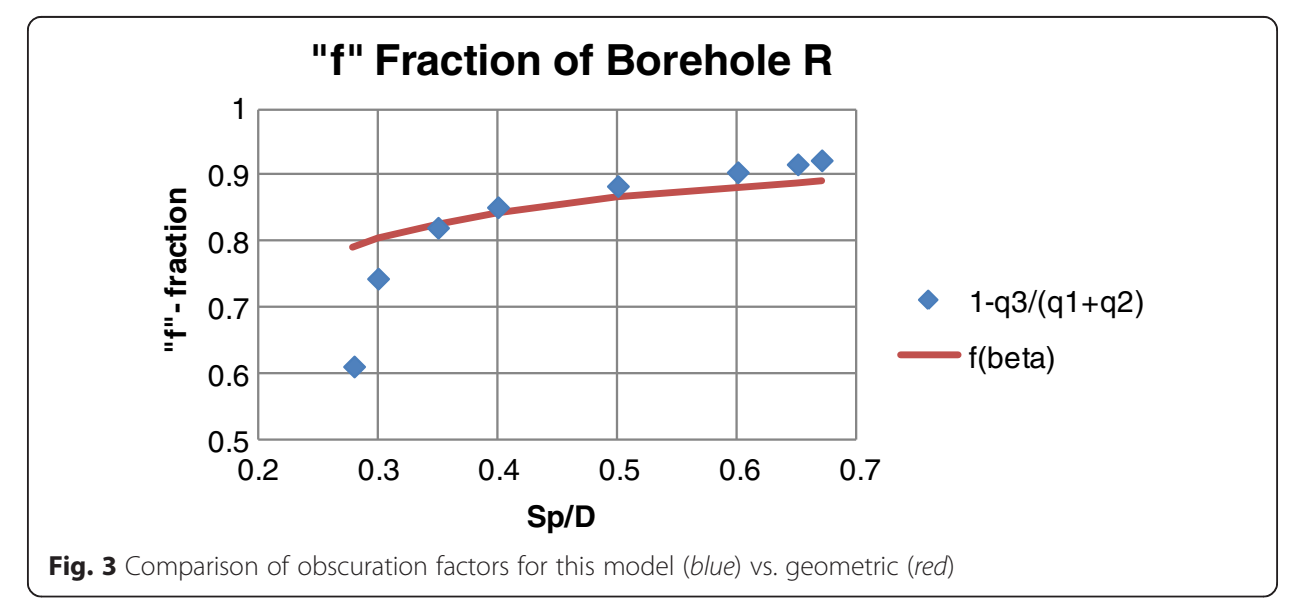




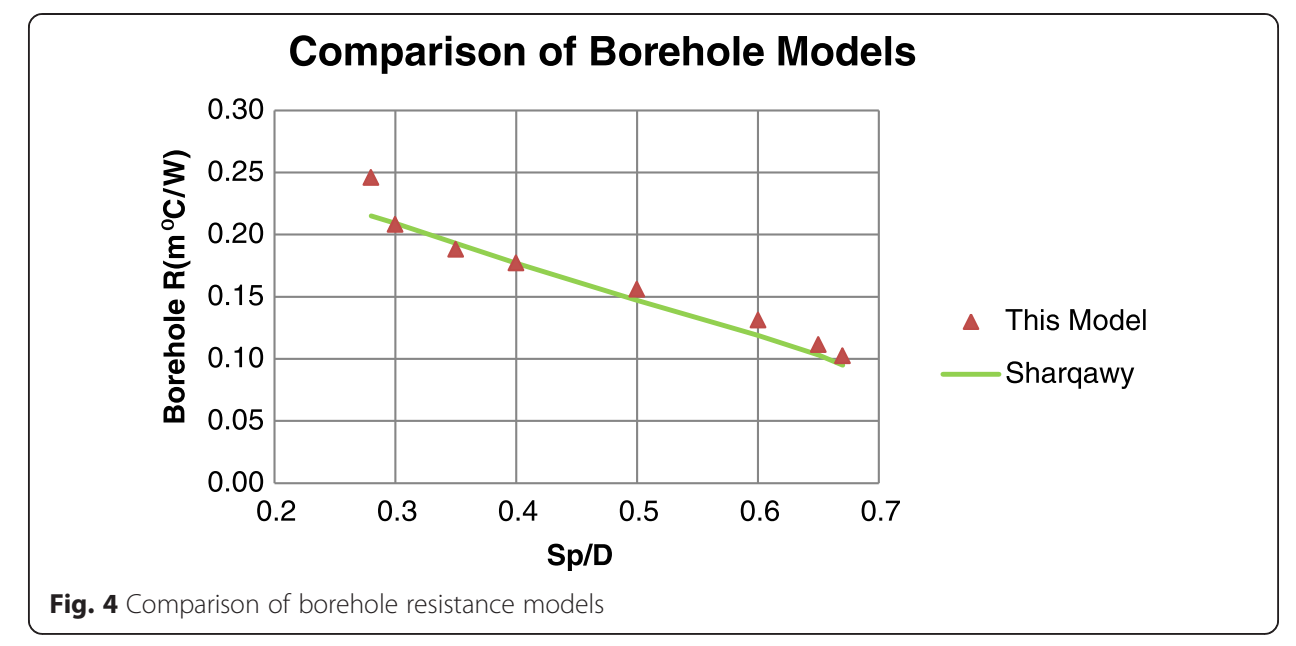

pipe conduction to the bore wall tends to dominate the response. In all cases, however, there is a $25 \%$ net BTR benefit to locating the pipe proximal to the bore wall.

\section{Methods}

\section{Extension to multi-loop borehole geometries}

In principle, adding additional loop(s) to a borehole should decrease borehole resistance by increasing the available pipe surface area for heat transfer. It should be noted, however, that the heat transfer effectiveness of an individual loop diminishes with each additional loop. This is because the heat transfer surface area of an individual loop for exchange with the bore wall is occulted by the presence of additional loops.

The method delineated here extends the single-loop BTR model by first defining the boundary in the borehole cross section that separates downcomer and upcomer pipe legs of a common temperature. Pipe loops are assumed to be connected in parallel.

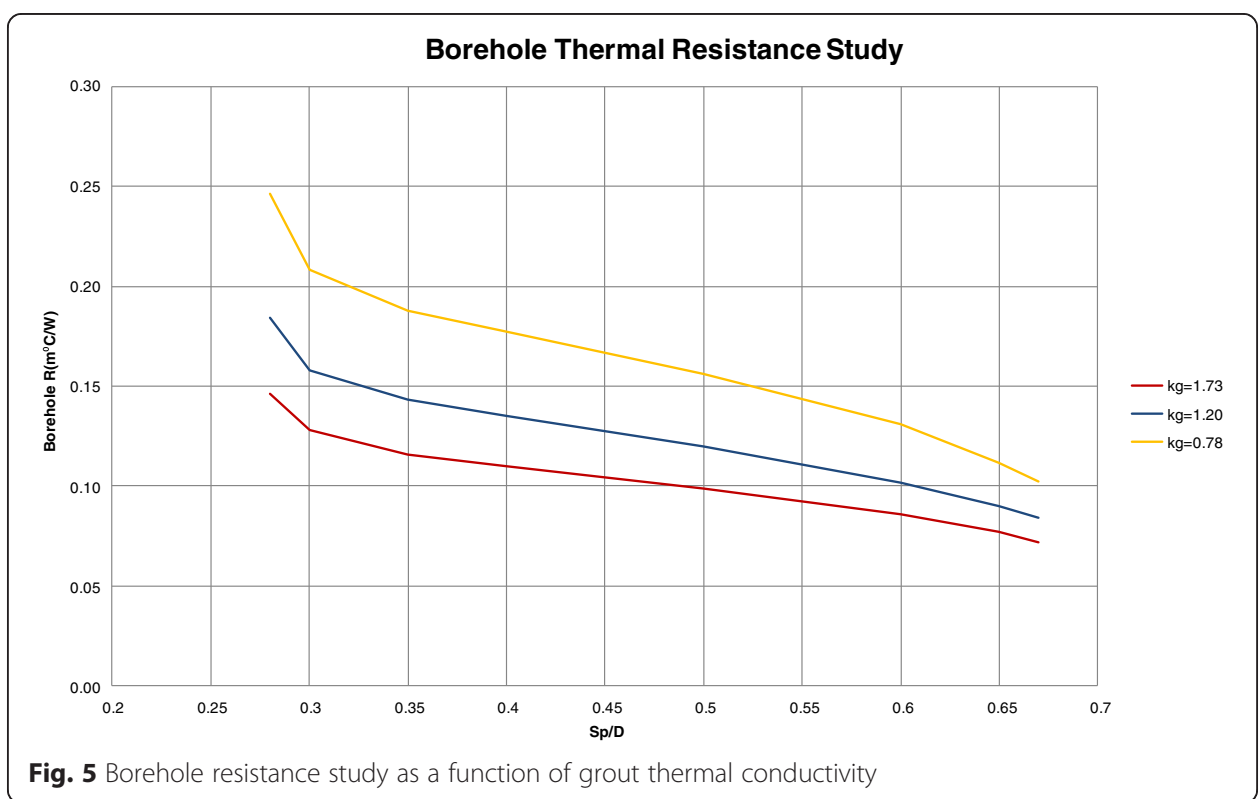




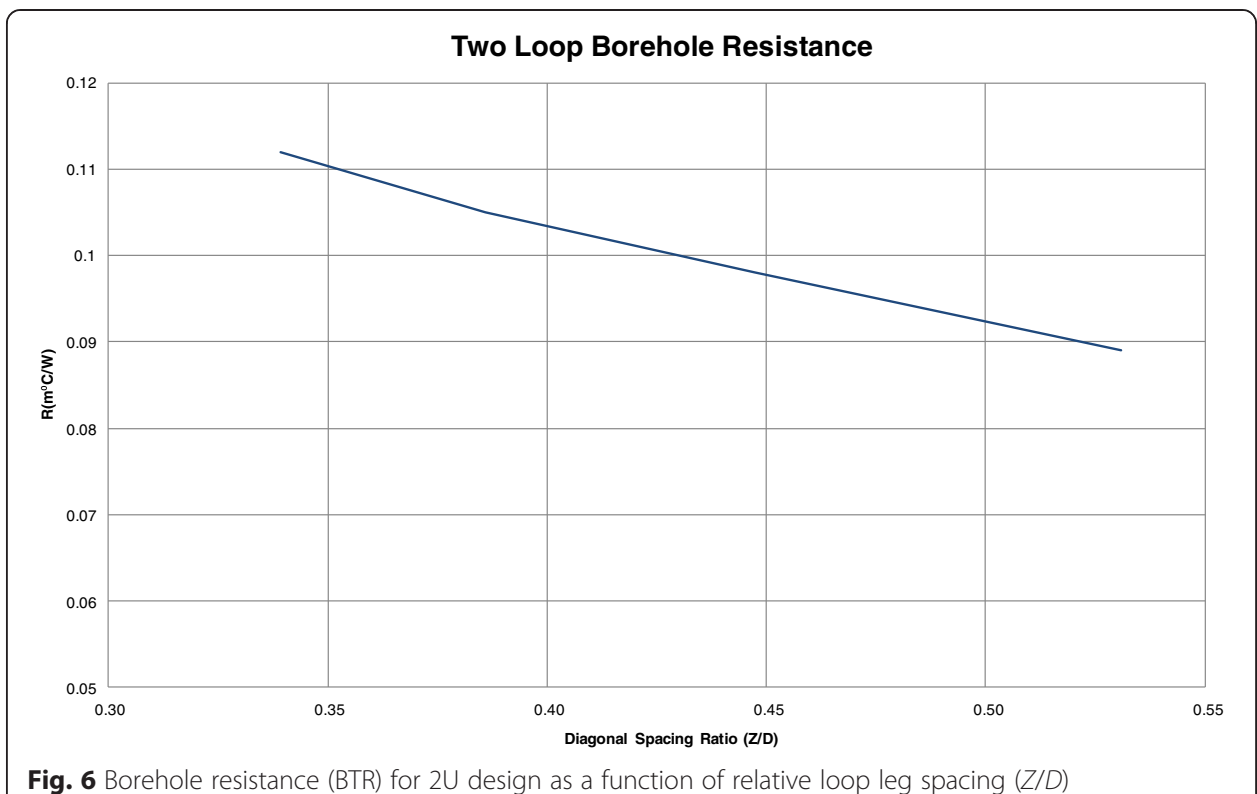

Fig. 6 Borehole resistance (BTR) for $2 \mathrm{U}$ design as a function of relative loop leg spacing (Z/D)

The thermal interaction between individual pipes across the boundary is treated independently and, without assigning legs of a common loop, using the single loop methodology presented previously. The total borehole resistance is assembled by summing the individual pipe-pipe resistances of a common spacing weighted by their geometric configuration factor. The configuration factor is developed by noting the number of occurrences of specific pipe-pipe geometries within the borehole. An example is offered to help clarify the procedure.

Starting with the two-loop borehole, shown in Fig. 8 leftmost diagram, the values of $R_{\mathrm{f}}$ are calculated for individual pipe on one side of the boundary line to the two pipes on the other side (diagonal and adjacent configurations). The resistances, $R_{\mathrm{p}}, R_{\mathrm{pp}}$, and $R_{f}$, are calculated for each configuration. The final (Fig. 6) BTR is composed of the contributions of each configuration. The example in Table 2 for $D=152 \mathrm{~mm}, d=33 \mathrm{~mm}$, and $k_{\mathrm{g}}=0.78 \mathrm{~W} / \mathrm{m}^{\circ} \mathrm{C}$ shows the assemblage of the final BTR value from equal contributions of each configuration.

To conform to the borehole, the ordered pipe planform geometries become square $(2 \mathrm{U})$, hexagonal $(3 \mathrm{U})$, and octagonal $(4 \mathrm{U})$, as indicated in Fig. 8. Pragmatically, in order to accommodate these configurations, the outside diameter of the assembly must remain within a maximum envelope, e.g., $114 \mathrm{~mm}$ in a $152-\mathrm{mm}$ bore, or $75 \%$ of the opening. To accomplish this, pipe sizes must shrink from $42 \mathrm{~mm}$ (1 1/4 in.) to $33 \mathrm{~mm}$ (1 in.) down to $27 \mathrm{~mm}(3 / 4 \mathrm{in}$.) as the number of loops increases. The constraints on allowable geometry impose restrictions on the range of pipe separations that are

Table 2 Two-loop borehole resistance model results

\begin{tabular}{llll}
\hline$N_{1000}=$ & 2 & & \\
Case 1. & $(\mathrm{mm})$ & $\mathrm{f}$ & $R_{\mathrm{b}}$ \\
\hline$Z=$ & 63.5 & 0.878 & 0.196 \\
$Z / \sqrt{ } 2=$ & 44.9 & 0.828 & 0.205 \\
\hline & & $A v g / 2 N_{\mathrm{L}}=$ & 0.100
\end{tabular}




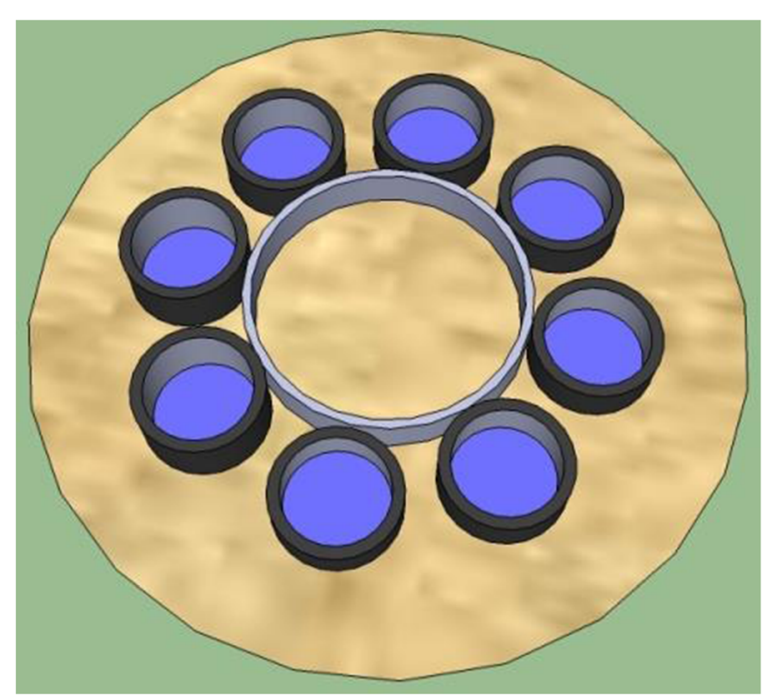

Fig. 7 Four-loop borehole configuration

feasible. Moreover, each of these multi-loop designs requires an assembly to affix the pipe to the desired geometry.

As an example, Fig. 7 shows four loops (eight pipes) arranged evenly around a hollow central form of diameter, $d_{\mathrm{cyl}}$.

The maximum (even) number of pipes $N_{\mathrm{x}}=2 N_{\mathrm{L}}$ that fit around the form is limited by:

$$
d \leq\left(d_{\mathrm{cyl}}+d\right) \sin \left(\pi / N_{\mathrm{x}}\right),
$$

where $d_{\text {cyl }}$ is the outside diameter of the form. In addition, there is a practical constraint based on the maximum diameter of the loop assembly that the borehole can comfortably accept,

$$
d_{\text {cyl }}+2 d \leq 0.75 D
$$

where $75 \%$ is deemed a reasonable limit. Combining (12) and (12A) leads to the condition:

$$
[0.75(D / d)-1] \sin \left(\pi / N_{\mathrm{x}}\right) \geq 1
$$

So, for example, with a $152-\mathrm{mm}$ (6 in.) bore and a $27-\mathrm{mm}(3 / 4 \mathrm{in}$.$) pipe size, the$ maximum number of pipes that fit the constraint is ten or, equivalently, five loops. The outside diameter (OD) of this assembly is then $\left(d_{\text {cyl }}+2 d\right)$, or, in this example, $114 \mathrm{~mm}$ (4.5 in.). Other sizes are possibly limited only by the assembly size impact on insertion in the borehole and the ability to insert a grout "tremie" pipe inside the ID of the form, or, ideally, use the form itself as the grout pipe.

To extend the previous model to the case of multi-pipe borehole geometries, under the assumption that the form itself offers negligible thermal isolation, one needs to simply specify the number of pipe loops, the diagonal pipe spacing, and then calculate the pipe-pipe shunt resistance for each configuration. The latter is based on the pipe-pipe spacing for each configuration, as shown in Fig. 8. 

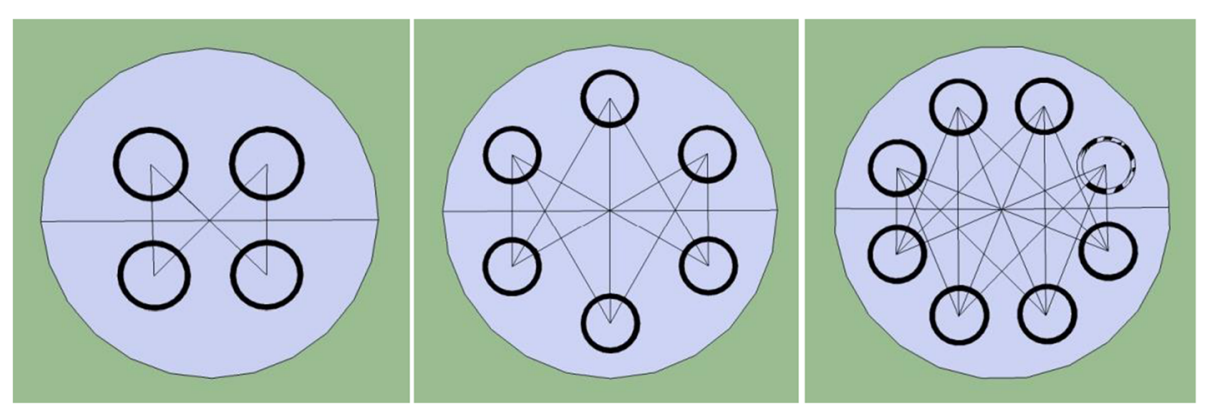

Fig. 8 Compilation of thermal separations between pipes for two-, three-, and four-loop assemblies

The horizontal line delineates pipe of a common temperature (downcomer vs. upcomer legs). Table 3 summarizes the spacing and number of configurations for each loop geometry, where $Z$ is the fixed diagonal c-c spacing. From this table, the shunt spacing for each separate configuration is identified and the shunt resistance, $R_{\mathrm{s}}$, can be computed for each configuration separately. This value, then, is inserted into the borehole resistance matrix to derive the obstruction factor, $f$.

The final borehole resistance for the multi-loop assembly is calculated from:

$$
\mathrm{BTR}=\Sigma\left[R_{\mathrm{bi}}(\mathrm{CF})_{i}\right] / N_{\mathrm{L}}
$$

where $R_{\mathrm{b}}$ is the borehole resistance for a single $(Z)$ configuration, multiplied by $\mathrm{CF}$, its configuration fraction, all summed over the number of configurations from $i=1$ to $N_{\mathrm{L}}$.

One of the advantages of additional loops is seen in the " $N_{\mathrm{L}}$ " factor that appears in the denominator which decreases borehole resistance as loops are added. An additional benefit is that the pipe wall thickness, assuming a fixed DR for pressure rating, decreases as the pipe gets smaller to accommodate the loops.

\section{Results}

Using the method outlined in this paper, a compilation of multi-loop borehole resistance is provided in Fig. 9 for specific loop designs and values of the pipe spacing ratio, $d / D$. The reduction in borehole resistance as additional loops are added is dramatic. This is especially noticeable with the addition of a second loop.

Table 3 Multi-loop pipe-pipe spacing for shunt analysis

\begin{tabular}{llll}
\hline$N$ loops & $S_{p}$ & Configuration occurrences & Configuration fraction (CF) \\
\hline 1 & $Z$ & 1 & 1 \\
\hline 2 & $Z$ & 2 & $1 / 2$ \\
& $Z / \sqrt{ } 2$ & 2 & $1 / 2$ \\
\hline 3 & $Z$ & 3 & $1 / 3$ \\
& $0.866 Z$ & 4 & $4 / 9$ \\
& $Z / 2$ & 2 & $2 / 9$ \\
\hline 4 & $Z$ & 4 & $1 / 4$ \\
& $0.9239 Z$ & 6 & $3 / 8$ \\
& $0.707 Z$ & 4 & $1 / 4$ \\
& $0.3827 Z$ & 2 & $1 / 8$ \\
\hline
\end{tabular}




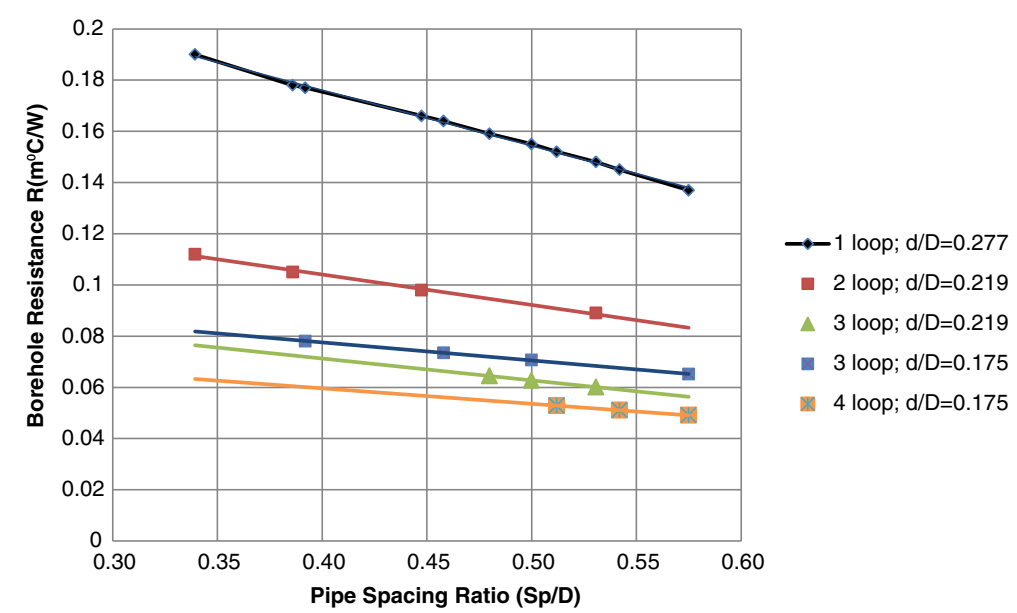

Fig. 9 BTR at $k_{g}=0.78 \mathrm{~W} / \mathrm{m}^{\circ} \mathrm{C}$ as a function of relative pipe spacing and loop designs

By constraining the OD of the multi-pipe loop assembly to $75 \%$ of the bore diameter, the study considered the benefit of additional loops. Fig. 10 shows that the borehole resistance decreases dramatically and was found to be inversely proportional to the number of loops to the power of 0.86 .

Figure 10 compares BTR values of multiple loop designs reported by specific loop manufacturers to the predictions of this model. In addition to the single-loop match (Fig. 4), there are two additional points of validation:

- From thermal measurements by Bowman Geothermal of REHAU 1-in. double-loop product in side-by-side installations, they report a BTR of $0.11\left(\mathrm{PEX}_{2}\right)$, a $40 \%$ reduction from single loop, which, after adjustment for HDPE, matches the model with an RMS error of $1.5 \%$.

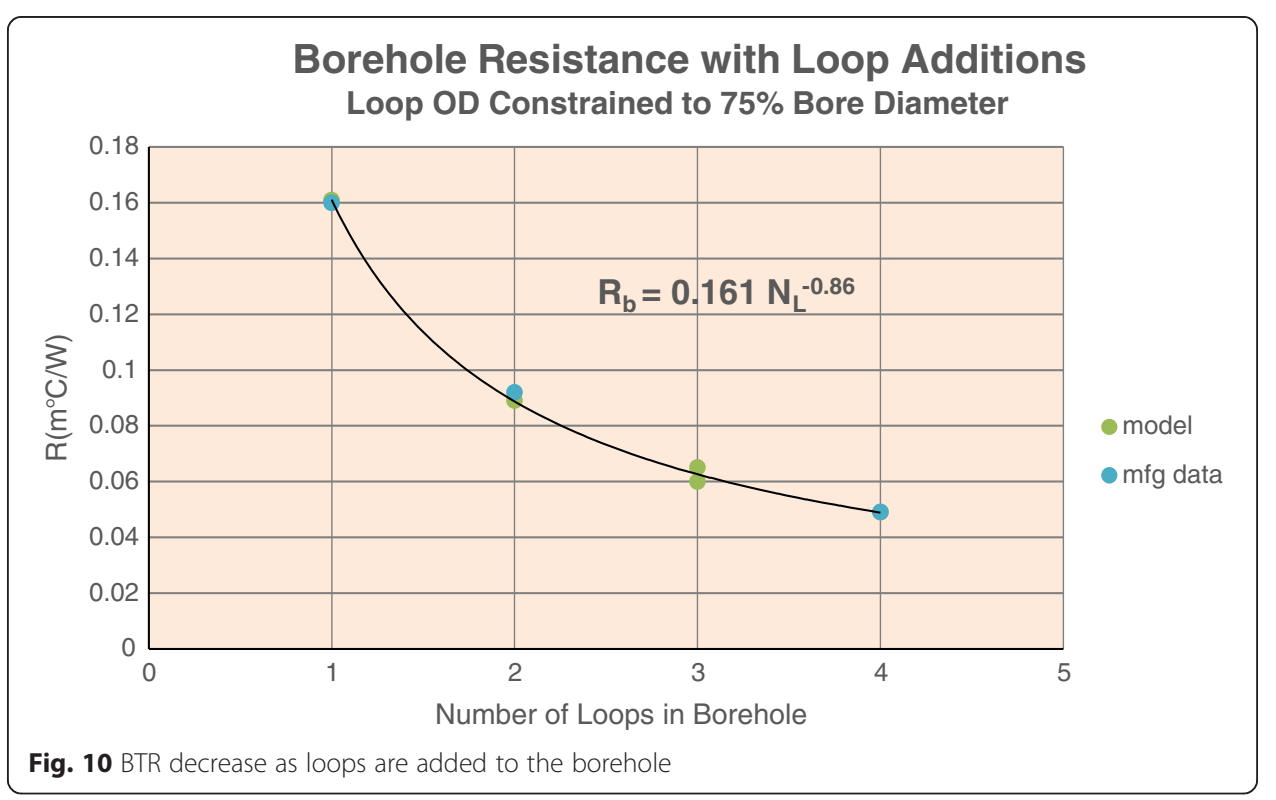


- Agreenability (2014) report a BTR of $0.049 \mathrm{~m}^{\circ} \mathrm{C} / \mathrm{W}$ in an application of their Twister $^{\text {Tx }}$ four-loop 3/4-in. pipe technology, which compares favorably to predictions exhibited in Fig. 9.

At some point with addition of multiple loops, the borehole resistance model effectively transitions to a central pipe equivalent diameter, $d_{\text {eq }}$, with a grout gap defined by:

$$
R_{\mathrm{b}}=R_{\mathrm{p}} / 2 N_{\mathrm{L}}+\mathrm{LN}\left(D / d_{\mathrm{eq}}\right) /\left(2 \pi k_{\mathrm{g}}\right),
$$

where $(Z+d) \leq d_{\mathrm{eq}} \leq\left(2 N_{\mathrm{L}}-2\right) d$ for $N_{\mathrm{L}}=2,3$, or $\left(2 N_{\mathrm{L}}-1\right) d$ for $N_{\mathrm{L}}=2$. The equivalent diameter is the wetted pipe perimeter limited between the smooth OD of the assembly and the exposed scalloped perimeter of the individual pipe. In this case, the pipe wall between pipes in the assembly becomes adiabatic, except for the end pipe that are at different temperatures.

If the assembly was designed such that the adjacent pipe in the assembly was at different temperatures, then, of course, this would diminish performance because of thermal shunting. Rather, if the assembly could be arranged to segregate pipe of the same temperature (downcomers and upcomers), as suggested in Fig. 11a, then, this might indeed improve performance. An alternate loop design, shown in Fig. 11b, eliminates the intermediate adiabatic walls between pipe in Fig. 11a, in favor of a custom kidney extruded shape. This design by ARB Geowell (2014) eliminates the need for an assembly of smaller pipe in favor of coiled pipe halves that must be joined with a molded transition from kidney pipe to $11 / 2$-in. round pipe for connections.

The utility of the proposed borehole thermal model is such that it can be easily extended from simple loops to more complex multi-pipe and custom shape loop configurations. The model addresses only the thermal resistance inside the borehole (BTR), and not the diffusion component into the surrounding formation. The benefit is that it can be incorporated easily into existing software, such as GLHEPRO, to handle multiloop borehole configurations, avoiding the details of constructing custom numerical models through FEFLOW.

The model produces reasonable results that support the data published by others. The extension of the model to multiple pipe loops in a single borehole is accomplished by (1) defining the mid-plane boundary between downcomer and upcomer pipe, (2) calculating the borehole resistance for each pipe-pipe separation across the boundary, (3) multiplying by the relative number of occurrences of each configuration to yield an

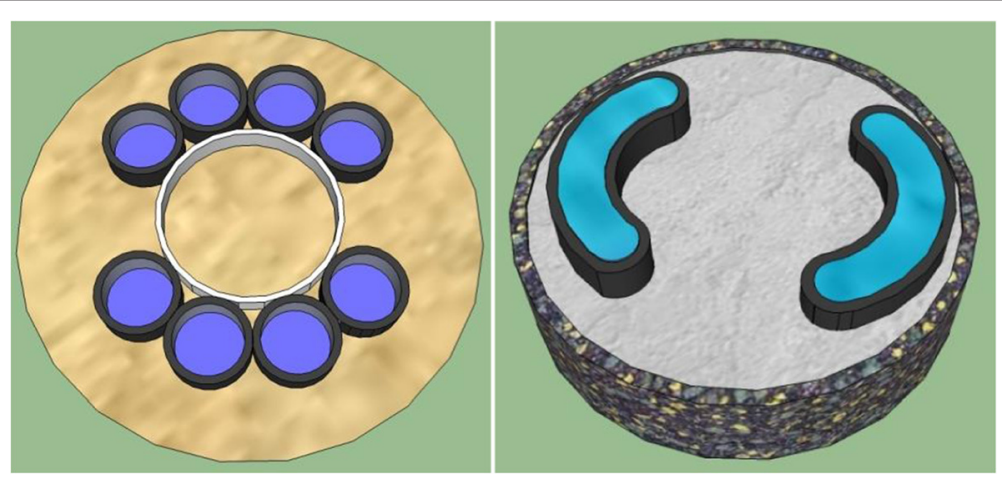

Fig. 11 a Segregated pipe assembly. b Extruded kidney pipe deployment 
average borehole resistance for a representative loop, and finally (4) dividing by the number of loops. Since the loop to bore wall temperature difference is controlled by the product, $q\left(R_{\mathrm{b}}\right)$, it is noteworthy that it makes no difference whether this is treated as a single loop, in which case $\left(q / N_{\mathrm{L}}\right) R_{\mathrm{b}}$, or the full multi-loop design, $q\left(R_{\mathrm{b}} / N_{\mathrm{L}}\right)$.

The benefit and practicality of implementing multiple loop borehole designs to improve performance and/or reduce installation cost is arguable. The use of a thermally enhanced grout with a single loop appears to lower borehole resistance by $30 \%$ over neat bentonite grout at standard U-bend separations, despite higher thermal shunting between the legs of the loops. But, unless the pipe legs can be guaranteed to be separated and not twisted and contacting over a substantial length of the bore, this $30 \%$ benefit may never be realized in practice. Physical separation, such as the use of GeoClips, is at least as beneficial as thermally enhanced grout. With this in mind, the obvious benefit of multiple loops in reducing borehole resistance is increased surface area for heat transfer and thinner HDPE walls that result from employing smaller diameter pipe loops. Another advantage to multiple loops is in lowering the pressure drop of the ground heat exchanger, which can be as much as $35 \%$. This benefit develops from dividing the flow into multiple pipe loops of a given cross section as well as shortening the length. In operation, this can save considerable pump energy over the year.

With that said, the question remains whether the assembly of pipe loops can be costeffective with the benefit of less required drilling. On paper, the savings in drilling more than offsets the extra cost of multiple pipe assembly, which ultimately means that plastic is less expensive than the lifecycle operation of the drill rig. Certainly, there are excellent targets for commercialization of new loop technology, such as commercial applications where space for the loop field is always an issue, and the opportunity to repurpose abandoned water wells that could serve residential customers without extending the depth of the well. Ultimately, driller pricing and competition will prove the winner.

\section{Conclusions}

A borehole thermal model for vertical loops was developed from a modified shape factor analysis. An interference factor, $f$, defined by $\left(1-q_{\text {shunt }} / q\right)$, the relative size of the thermal shunt between the loop segments, was employed as the modification required to properly model borehole thermal resistance. The model predictions were compared to reported results and found to match quite nicely over a range of pipe sizes and spacing. Following this success, the model was extended to multi-pipe loop geometries consisting of two-, three-, and four-loop assemblies in a single borehole and a custom kidney extrusion. The borehole resistances were calculated for each of these configurations and presented as a compilation of predicted performance. These predictions were compared to the available data reported by manufacturers of multi-pipe loop assemblies and found to give reasonable results.

\footnotetext{
Abbreviations

$T_{\mathrm{p}}$ : temperature of pipe loop segment, ${ }^{\circ} \mathrm{C} ; T_{\mathrm{b}}$ : temperature of borehole perimeter, ${ }^{\circ} \mathrm{C} ; \Delta T_{1 n}$ : temperature difference pipe 1 to $(n=b$ bore; $n=2$ pipe 2$),{ }^{\circ} \mathrm{C} ; q_{n}$ : exchange heating rate (pipe to bore wall or pipe to pipe), $\mathrm{W} / \mathrm{m} ; R_{\mathrm{p}}$ : thermal resistance of pipe (convection and pipe wall), $\mathrm{m}^{\circ} \mathrm{C} / \mathrm{W} ; R_{\mathrm{fs}}$ : single pipe thermal resistance (pipe to bore wall), $\mathrm{m}^{\circ} \mathrm{C} / \mathrm{W}$; $R_{f}$. effective thermal resistance (pipe to bore wall), $\mathrm{m}^{\circ} \mathrm{C} N$; $D$ : borehole diameter, $\mathrm{m}$; $d$ : outside diameter of the loop pipe, m; DR: dimension ratio: pipe diameter to wall thickness; $S_{p}$ : center to center spacing between pipe, $m$; $h_{\mathrm{cv}}$ : convection heat transfer coefficient, $\mathrm{W} / \mathrm{m}^{2 \circ} \mathrm{C} ; k_{\mathrm{p}}$ : HDPE pipe thermal conductivity, $\mathrm{W} / \mathrm{m}^{\circ} \mathrm{C}_{;} R_{\mathrm{s}}$ : pipe-pipe shunt thermal resistance, $\mathrm{m}^{\circ} \mathrm{C} / \mathrm{W} ; k_{\mathrm{g}}$ : grout thermal conductivity, $\mathrm{W} / \mathrm{m}^{\circ} \mathrm{C}_{;} d_{\mathrm{r}}$ : diameter ratio $=d / D_{;} S_{\mathrm{r}}$ : spacing ratio $=S_{\mathrm{p}} / d_{;} X_{\mathrm{pp}}$ : pipe to pipe
} 
dimension $=\left[2\left(S_{p} / d\right)^{2}-1\right] ; X_{f}$ : pipe to bore wall dimension $=1 / 2\left[d_{r}\left(1-S_{r}^{2}\right)+1 / d_{r}\right]$; $f$ loop pipe interference factor in thermal exchange; $d_{c y l}$ : central cylinder diameter, $m$; $N_{L}$ : number of loops in borehole; $C F$ : configuration fraction; $R_{\mathrm{b}}$ : borehole thermal resistance (BTR), $\mathrm{m}^{\circ} \mathrm{C} / \mathrm{W} ; d_{\mathrm{eq}}$ : equivalent diameter of pipe loops actively exchanging heat, $\mathrm{m} ; \mathrm{Z}$ : diagonal $\mathrm{c}-\mathrm{c}$ distance between pipe in multi-loop geometry, $\mathrm{m}$.

\section{Competing interests}

The author declares that he has no competing interests, although ARB Geowell owns the patent for K-Pipe, a kidney pipe custom extrusion. The performance benefit of this pipe was treated objectively within the context of multiple pipe loops. The author has no financial commitment from the company to support the publication of this work nor derives a benefit from its publication.

Received: 16 September 2014 Accepted: 29 April 2015

Published online: 17 June 2015

\section{References}

Al-Koury R, Bonnier PG, Brinkgreve RB (2005) Efficient finite element formulation for geothermal heating systems. Part l: steady-state. Int J Numerical Methods Eng 63(7):933-1013, Pt. II: Transient, IJNME 67 (2006) 5, 725-745

Agreenability, J R (2014) TWISTER high efficiency geothermal heat exchanger. IGSHPA Conference, Baltimore, MD ARB Geowell, Koenig A (2014) A new HDPE pipe loop for single well residential opportunity. Paper presented at the PGWA winter conference, Grantsville, PA, 23-24 January 2014

Beier RA, Ewbank GN (2012) In-situ thermal response test interpretations: OG and E ground source heat exchange study. IGSHPA, OKSU

Crecraft H, Mahlmann J, Rehau in-situ thermal performance testing Bowman Geothermal, LLC, Chantilly, VA: http://www.rehau.com/download/866550/borehole-thermal-conductivity-report.pdf

Diersch HJ, Bauer D, Heidemann W, Rühaak W, Schätzl (2010) Finite element formulation for borehole heat exchangers in modeling geothermal heating systems. FEFLOW, DHI-WASY software, White Papers Volume V. 5:5-96.

Eskilson P, Claesson J (1988) Simulation model for thermally interacting heat extraction boreholes. Numerical Heat Transfer 13(2):149-165

GLD: www.seventhwave.org/hygchp

GLHEPRO: https://hvac.okstate.edu/glhepro/overview

Gu Y, O'Neal D (1998) Development of an equivalent diameter expression for vertical U-tubes used in ground-coupled heat pumps. ASHRASE Trans 104(2):9

Hellström G (1991) Ground heat storage, thermal analyses of duct storage systems, doctoral thesis. Department of Mathematical Physics, University of Lund, Lund, Sweden

Holman JP (1981) Heat transfer. McGraw-Hill, New York, pp 68-71

HyGCHP: www.ecw.org/hygchp

Koenig A, Helmke M (2014) Development of a thermal resistance model to evaluate wellbore heat exchange efficiency. Int J Energy Environ 5(3):297-304

Liao Q, Zhou C, Cui W, Jen T (2012) Effective borehole thermal resistance of a single U-tube ground heat exchanger. Numerical Heat Transf 62:197-210

Phillippe M, Bernier M, Marchio D (2010) Sizing calculation spreadsheet vertical geothermal borefields. ASHRAE J 7:20-28

Redmund CP (1999) Borehole thermal resistance: laboratory and field studies. ASHRAE Trans 105:439-445

Sagia Z, Stegou A, Rakopoulos C (2012) Borehole resistance and heat conduction around vertical ground heat exchangers. The Open Chem Eng J 6:32-40

Sharqawy MH, Mokheimer EM, Hassan MB (2009) Effective pipe-to-borehole thermal resistance for vertical ground heat exchangers. Geothermics 38:271-277

TRNSYS: sel.me.wisc.edu/trnsys/downloads/trnsedapps/gchpdemo/overview.htm; Klein, S.A., et al., TRNSYS Manual, "A Transient Simulation Program", Solar Energy Laboratory, University of Wisconsin, Version 14.2, for Windows, Sep 1996. Shonder, John and Hughes (1997) Patrick from ORNL (Oak Ridge National Laboratory). Richard Stockton College. Zarrella A, DeCarli M, Galgaro A (2013) Thermal performance of two types of energy foundation pile: helical pipe and triple U-tube. Appl Therm Eng 61(2):301-310

\section{Submit your manuscript to a SpringerOpen ${ }^{\circ}$ journal and benefit from:}

- Convenient online submission

- Rigorous peer review

- Immediate publication on acceptance

- Open access: articles freely available online

- High visibility within the field

Retaining the copyright to your article 